\title{
Quantitative Trait Loci Associated with Rotylenchulus reniformis Host Suitability in Soybean
}

\author{
Juliet Wilkes, ${ }^{1, \dagger}$ Christopher Saski, ${ }^{1}$ Mariola Klepadlo, ${ }^{2}$ Benjamin Fallen, ${ }^{3}$ and Paula Agudelo ${ }^{1}$ \\ ${ }^{1}$ Department of Plant and Environmental Sciences, Clemson University, Clemson, SC 29634 \\ 2 Division of Plant Sciences, University of Missouri, Columbia, MO 65201 \\ ${ }^{3}$ Pee Dee Research and Education Center, Clemson University, Florence, SC 29506 \\ Accepted for publication 27 April 2020.
}

\begin{abstract}
Reniform nematode (Rotylenchulus reniformis) is a yield-limiting pathogen of soybean (Glycine max) in the southeastern region of the United States. A population of 250 recombinant inbred lines (RIL) $\left(\mathrm{F}_{2: 8}\right)$ developed from a cross between reniform nematode resistant soybean cultivar Forrest and susceptible cultivar Williams 82 was utilized to identify regions associated with host suitability. A genetic linkage map was constructed using single-nucleotide polymorphism markers generated by genotyping-by-sequencing. The phenotype was measured in the RIL population and resistance was characterized using normalized and transformed nematode reproduction indices in an optimal univariate cluster analysis. Quantitative trait loci (QTL) analysis

other analysis ( $r r n-1)$, and one on chromosome 11 ( $r r n-3)$. While $r r n-1$ and $r r n-3$ have been reported associated with reduced reproduction of reniform nematode, this is the first report of the $r r n-2$ region associated with host suitability to reniform nematode. The resistant parent allele at $r r n-2$ showed an inverse relationship with the resistance phenotype, correlating with an increase in nematode reproduction or host suitability. Several candidate genes within these regions corresponded with host plant defense systems. Interestingly, a characteristic pathogen resistance gene with a leucine-rich repeat was discovered within $r r n-2$. These genetic markers can be used by soybean breeders in marker-assisted selection to develop lines with resistance to reniform nematode.
\end{abstract} using normalized phenotype scores identified two QTLs on each arm of chromosome 18 ( $r r n-1$ and $r r n-2)$. The same QTL analysis performed with $\log _{10}(x)$ transformed phenotype data also identified two QTLs: one on chromosome 18 overlapping the same region in the
Keywords: genetics and resistance, host suitability, nematology, quantitative trait loci, resistance, Rotylenchulus reniformis, soybean
Soybeans Glycine $\max$ L. Merrill are an important commodity crop in the southeastern region of the United States in both production acres and economic value (soystats.com). Reniform nematode (Rotylenchulus reniformis Linford and Oliveira) is a sedentary, root-feeding plant parasitic nematode known to infect over 300 species of plant species worldwide and a known pathogen of many row crops in the southeast, including soybean (McGawley et al. 2011; Robinson et al. 1997). Reniform is a prolific pathogen that is associated with a wide variety of soil textures and has a life cycle reported to be less than 20 days in optimal conditions, producing an average of 60 eggs per female (Rebois 1973). Annual surveys have revealed the impact of reniform nematode on the production of soybean in southern states, estimating a yield loss of $0.21 \%$ in each state in 2018 , which equates to a total average loss of 1.73 million bushels of soybean (Allen et al. 2018). Currently, the most sustainable and cost-effective management practice for controlling high reniform nematode pressure is to employ resistant cultivars. Planting resistant soybean cultivars not only prevent major yield loss but also decreases reniform nematode populations in the soil, which is important for fields rotated with cotton (Gossypium hirsutum L.) or another susceptible crop. There are a number of resistant soybean germplasm in both plant introductions

†Corresponding author: J. E. Wilkes; jfultz@clemson.edu

Funding: Funding for this study was provided in part by the South Carolina Soybean Board.

*The $e$-Xtra logo stands for "electronic extra" and indicates that supplementary figures are published online.

The author(s) declare no conflict of interest.

(C) 2020 The American Phytopathological Society
(PIs) and released cultivars (Robbins and Rakes 1996; Robbins et al. $1999,2002)$. However, more studies are required to fully understand and characterize the diversity and sources of genetic resistance to reniform nematode in soybean. Initial studies in the 1980 s suggested resistance to reniform nematode in soybean was controlled by one (Williams et al. 1981) or two (Harville et al. 1985) recessive loci. Recent genotyping technologies has given insight to specific regions in the soybean genome associated with reniform nematode resistance. In 2007, three QTL regions were identified on chromosomes (Chrs.) 19, 18, and 11. The latter two regions on Chrs. 11 and 18 were confirmed using restriction fragment length polymorphism and single sequence repeat (SSR) markers in a recombinant inbred line (RIL) population from a cross between reniform nematode susceptible 'BSR101' and resistant PI 437654 (Ha et al. 2007). Another study also identified two regions in Chrs. 18 and 11 using both SSR and single nucleotide polymorphism (SNP) markers in PI 567516C (Jiao et al. 2015). Three SSR markers on Chr. 18 and one on Chr. 11 have also been linked to reniform resistance in a RIL population of 'Flyer' $\times$ 'Hartwig' (Lee et al. 2016). Klepadlo and colleagues (M. Klepadlo, R. T. Robbins, J. F. Wilkes, D. Crippen, V. Shankar, T. D. Vuong, P. Agudelo, and H. T. Nguyen, unpublished data) identified two QTL controlling reniform nematode resistance in PI 438489B on Chrs. 11 and 18 using the Universal Soybean Linkage Panel (USLP 1.0) and next-generation whole-genome resequencing technology. All four QTL identification studies were phenotypically screened using a reniform nematode culture derived from the state of Arkansas. Although different races or genotypes of reniform nematode have not been characterized to date, studies have shown genetic distinction between $R$. reniformis populations across the United States (Khanal et al. 2018). It should not be assumed that resistant host genotypes will uniformly respond to every population of reniform nematode. No study investigating genomics regions in soybean associated with reniform nematode 
resistance have utilized a U.S. reniform population outside of the state of Arkansas. Additionally, the soybean 'Forrest' has historically been used as the resistant check in reniform nematode resistance screenings, but no study has investigated the genetics in Forrest that harbor this resistant trait. Resistance to a nematode pathogen is measured by quantifying the nematode's reproduction on a host plant over an allotted time (Starr et al. 2002; Trudgill 1991). This method indirectly measures the host plant's ability to inhibit the nematode from infecting or completing its life cycle. Nematologists have used the term "host suitability" to more accurately define the degree of resistance or susceptibility (Sasser et al. 1984) The values of this measurement are usually given as a reproduction factor or index (RI) and have been reported in several formats: nontransformed or transformed by $\log _{10}(x)$ or $\log _{10}(x+1)$ (Ha et al. 2007; Klepadlo et al. 2018; Robbins et al. 2017). Resistant or unsuitable hosts are determined by comparing the RI of a test plant with the RI of a susceptible or resistant check or against a standardized index with specific ranges for resistance and susceptibility (Sasser et al. 1984). These methods may not provide an accurate depiction of the inheritance of resistance genes in a host plant mapping population. Both soybean cyst (Heterodera glycines Ichinohe) and reniform nematode species create a similar feeding structure inside the host plant, indicating a potentially similar genetic source of resistance (Rebois et al. 1968). Several studies have linked the 'Peking'-derived soybean cyst nematode resistance to reniform nematode resistance in soybean cultivars (Klepadlo et al. 2018; Rebois et al. 1970; Robbins and Rakes 1996). Peking-type resistance to soybean cyst nematode corresponds to a combination of two genes: rhgl on Chr. 18 and Rhg4 on Chr. 8. One such cultivar, 'Forrest' maturity group V, was released in the early 1970 s as a resistant cultivar to combat soybean cyst nematode (Hartwig and Epps 1973), carrying the Peking-derived rhgl and Rhg4 resistance genes. Historically, Forrest has been used as the reniform nematode resistant check in several studies. Both Forrest and 'Williams 82' maturity group III have been utilized in several studies that provide major contributions to Glycine max genomics research (Lightfoot 2008). There has been extensive research identifying the genes associated with resistance to soybean cyst nematode (Concibido et al. 2004; Cook et al. 2014; Yu and Diers 2017), but there remains a lack of depth in genetic studies for reniform nematode resistance to identify markers linked to resistance, genes responsible for resistance and a better understanding of the genetics underlying the distinction between soybean cyst resistance. Marker-assisted selection is a useful tool for plant breeders, particularly for traits that cost a lot of time and money phenotype. Advancements in genetic screening pipelines to characterize pathogen resistance has significantly reduced costs and made genotype discovery and validation a more efficient means of identifying phenotypes. Reduced representation sequencing techniques, such as genotyping-by-sequencing (GBS), have allowed for high-resolution markers to be identified without the cost of more extensive techniques, such as whole-genome sequencing (Sonah et al. 2013). SNPs are most commonly used markers in marker-assisted selection techniques due to their abundance in genomes and easy evaluation in assays (Guo et al. 2018; Shi et al. 2015). To associate SNP markers to reniform nematode resistance, a RIL developed from a cross between soybean cultivars Forrest and Williams 82 was genotyped and phenotyped for host suitability to a reniform nematode population collected from South Carolina. Sequences were generated using GBS and a linkage map was constructed from SNP markers within the population. The objective of this study was to identify SNP markers linked to host suitability to reniform nematode as conferred by the soybean cultivar Forrest.

\section{MATERIALS AND METHODS}

Reniform nematode resistance phenotyping of RIL population. A set of $250 \mathrm{~F}_{2: 8}$ RILs from Forrest $\times$ Williams 82 developed by the University of Missouri (Wu et al. 2011) was used in this study. For phenotype screening and nematode quantification, the 250 RILs were divided into 15 rounds, each round consisting 16 lines, performing three replicates of each line (26 lines in the final round). For each RIL, six 8-oz. Styrofoam cups were filled with $225 \mathrm{~cm}^{3}$ of sterilized soil (Wagram loamy sand texture, collected from the Edisto REC soybean field, South Carolina) and one seed was planted in each cup (Robbins et al. 2017). Six days after planting, three of the most uniform seedlings were selected for screening and the other three were discarded. The population parents, Williams 82 and Forrest, were included in each round as the susceptible and resistant check, respectively. The plants were grown in a growth room with $12 \mathrm{~h}$ of daylight, an average temperature of $30^{\circ} \mathrm{C}$, and watered daily using an automated irrigation system. The water amount was adjusted throughout the experiment to account for growing needs. Pots were arranged in randomized complete block design within the growth room. Six days after planting, each plant was inoculated with 2,000 $R$. reniformis vermiform nematodes suspended in $1 \mathrm{ml}$ of tap water. The inoculum was a reniform nematode population originally collected from a cotton field in St. Matthew's County, South Carolina. The population had been maintained on susceptible soybean cultivar, 'Braxton', for over 15 generations. Nematodes were collected from soybean roots and soil in the pot and used to inoculate test plants within $5 \mathrm{~h}$ of extraction. A 1,000- $\mu$ l clean pipette tip was inserted at the base of each plant near the tap root at a depth of approximately $1 \mathrm{inch}$. The prepared inoculum was injected in each hole below the soil surface using a micropipette. The plants were fertilized once with watersoluble 15-15-15 (N-P-K) 25 days after inoculation.

At 60 days after inoculation, the stems of each plant were cut above the soil line and discarded. The soil and roots from the cups were emptied into a 1-liter pitcher and the roots were gently rinsed of soil, bagged, and set aside. The soil remaining in the pitcher was mixed with high pressured water and then poured over no. 80 $(180 \mu \mathrm{m})$ and no. $500(20 \mu \mathrm{m})$ stacked sieves. This step was repeated twice more. The material collected on the no. 500 sieve was then processed using the sugar centrifugation process (Jenkins 1964) to separate the nematodes from the soil. The collected extraction was saved for counting. The roots from each pot were then placed individually in a beaker with enough $0.5 \% \mathrm{NaOCl}$ solution to cover the roots and vigorously agitated for $3 \mathrm{~min}$ to dislodge egg masses from roots (Hussey and Barker 1973). The solution was then rinsed over no. 80 and no. 500 stacked sieves, and eggs from the bottom sieve were collected for counting. The total count of reniform vermiform and eggs from extracted soil and roots from each of three replicates were totaled and an average of the three replicates were used to calculate the reproduction index $(\mathrm{RI}=$ total egg and vermiform count/initial inoculation count) for each of the 250 lines.

To combine data from all 250 RILs, the RI of each line was normalized to the RI of the susceptible check, Williams 82, in the respective screening round. The distribution of RI values was tested for normality using the Shapiro-Wilk goodness of fit statistic in JMP 14.1 (SAS Institute Inc., Cary, NC, 2019/R program). Broad-sense heritability was calculated as described in Wu et al. (2009).

The normalized RI for each line was further transformed by $\log _{10}(x)$ in attempt to normalize. Transformed RI values were analyzed using an unsupervised, optimal univariate cluster analysis provided in the $\mathrm{R}$ software package Ckmeans. 1d.dp (Wang and Song 2011). The optimal number of clusters, $k$, was determined by calculating Bayesian information criterion and minimizing the differences in $k$-means of each cluster. Graphics were produced using custom $\mathrm{R}$ scripts (M. Klepadlo, R. T. Robbins, J. F. Wilkes, D. Crippen, V. Shankar, T. D. Vuong, P. Agudelo, and H. T. Nguyen, unpublished data).

DNA extraction. Soybean DNA was extracted from approximately $100 \mathrm{mg}$ of newly developed leaf tissue collected from each RIL, and the parents from the same plant was used in the phenotype screening. Tissue was placed in deep 96-well plates and lyophilized at $-40^{\circ} \mathrm{C}$ for $24 \mathrm{~h}$. The tissue in each well was finely ground by adding one metal grinding ball (OPS Diagnostics, size 5/32") to each well and placed on a $2010 \mathrm{Geno} /$ Grinder for at $1,500 \mathrm{rpm}$ for $45 \mathrm{~s}$. 
The extraction protocol was modified from a DNA extraction protocol developed by Washington State University (Edge-Garza et al. 2014) and is as follows: DNA extraction buffer was made using $10 \mathrm{ml}$ of $1 \mathrm{M}$ Tris, $10 \mathrm{ml}$ of $0.5 \mathrm{M}$ EDTA, $20 \mathrm{ml}$ of $5 \mathrm{M} \mathrm{NaCl}, 10 \mathrm{ml}$ of $0.05 \%$ sodium dodecyl sulfate, and $50 \mathrm{ml}$ of diethyl pyrocarbonate (DEPC) water. For each 96 well tray, $60 \mathrm{ml}$ of the DNA extraction buffer was combined with $0.6 \mathrm{~g}$ of $1 \%$ PVP4O, $0.078 \mathrm{~g}$ of $0.13 \%$ dieca, $0.06 \mathrm{~g}$ of $0.1 \% \mathrm{DTT}$, and $0.06 \mathrm{~g}$ of $0.1 \%$ ascorbic acid. The solution was kept in a $65^{\circ} \mathrm{C}$ water bath. After removing the grinding ball, $500 \mu \mathrm{l}$ of the prepared extraction buffer was added to each sample and gently inverted. The samples were incubated at $65^{\circ} \mathrm{C}$ and gently agitated on a shaker for $30 \mathrm{~min}$. The trays were then moved to $-20^{\circ} \mathrm{C}$ for $15 \mathrm{~min}$. Afterward, $250 \mu \mathrm{l}$ of $4^{\circ} \mathrm{C} 6 \mathrm{M}$ ammonium acetate was added to each sample. The trays were then returned to $-20^{\circ} \mathrm{C}$ for 15 additional minutes. The samples were centrifuged at $4,200 \mathrm{rpm}$ for $30 \mathrm{~min}$ at $4^{\circ} \mathrm{C}$. The supernatant in each well was then transferred to a new receiver plate and filter 96-well plate (PALL filter number 830$)$ and centrifuged $(3,200 \mathrm{rpm})$ for $7 \mathrm{~min}$ at $4^{\circ} \mathrm{C}$. The filter was removed and all samples were checked for uniform volume. DNA was precipitated by adding $1.5 \mu \mathrm{l}$ of glycogen $(10 \mathrm{mg} / \mathrm{ml})$ and $240 \mu \mathrm{l}$ of isopropanol to each sample and incubated for $30 \mathrm{~min}$ at $-20^{\circ} \mathrm{C}$. Following incubation, plates were centrifuged at 4,200 rpm, and the isopropanol was decanted out. The DNA pellet was washed twice, decanting after each wash, with $500 \mu \mathrm{l}$ of $70 \%$ ethanol and then air dried for $15 \mathrm{~min}$ to remove residual ethanol. Samples were resuspended in $40 \mu \mathrm{l}$ of double-distilled (dd) $\mathrm{H}_{2} \mathrm{O}$.

DNA quality and quantity were assessed on a Thermo Scientific (Wilmington, DE) Nanodrop 8000 spectrophotometer and a Quibit. DNA concentrations were normalized to $10 \mathrm{ng} / \mu \mathrm{l}$ for use in GBS library preparation.

GBS library preparation. Reduced representation nextgeneration sequencing techniques were employed to achieve high-density genetic screening through GBS. Five independent samples were run for each parent line and one sample for each RIL. The GBS library preparation protocol was performed using a modified protocol (Elshire et al. 2011). Restriction enzymes PstI and $\mathrm{MseI}$ were chosen to use in this experiment based on a trial digestion with sample DNA resulting in fragments ranging 200 to 1,000 bp (Supplementary Fig. S1).

In short, a digestion mixture was made $(2.0 \mu \mathrm{l}$ of NEB CutSmart buffer $10 \times, 1.0 \mu \mathrm{l}$ of $P s t \mathrm{I}, 0.5 \mu \mathrm{l}$ of $\mathrm{MseI}, 0.2 \mu \mathrm{l}$ of RNase, and $16.3 \mu \mathrm{l}$ of $\mathrm{H}_{2} \mathrm{O}$ ) and $20 \mu \mathrm{l}$ was added to each sample. The plates were placed on a shaker for $30 \mathrm{~min}$, briefly spun down in centrifuge, and placed in the thermocycler for digestion $\left(37^{\circ} \mathrm{C}\right.$ for $3 \mathrm{~h}, 80^{\circ} \mathrm{C}$ for $20 \mathrm{~min}, 4^{\circ} \mathrm{C}$ for storing). Unique adaptors and barcodes designed for Illumina sequencing were added to the fragments along with $30 \mu \mathrm{l}$ of ligation solution $(5.0 \mu \mathrm{l}$ of Promega T4 ligase buffer, $0.8 \mu \mathrm{l}$ of T4 ligase, and $24.2 \mu \mathrm{l}$ of $\mathrm{ddH}_{2} \mathrm{O}$ per sample) and agitated for $20 \mathrm{~min}$. Samples were then briefly spun down and placed in the thermocycler for $16 \mathrm{~h}$ at $16^{\circ} \mathrm{C}$, followed by $20 \mathrm{~min}$ at $65^{\circ} \mathrm{C}$ to deactivate ligase. Plates were put on a shaker for $12 \mathrm{~min}$ and then spun down in a centrifuge briefly. Samples were pooled by taking $10 \mu \mathrm{l}$ of each sample from one plate and combining it in a $15 \mathrm{ml}$ tube with $5.0 \mathrm{ml}$ of PB buffer (Qiagen QIAquick PCR purification kit Cat number/ID 28106). The sample solution was passed through the Qiagen filter column and DNA was eluted in $50 \mu \mathrm{l}$ of EB buffer provided in Qiagen kit. Pooled samples were optimally amplified for 18 cycles for generation of desired fragment size (200 to $700 \mathrm{bp}$ ) using primers complement to adaptor sequence. Products were cleaned using Mag-bind PCR clean-up 96 kit (OMEGA Bio-Tek M1382). Quality and quantity of the DNA samples were confirmed using a Qubit and Aligent 2100 Bioanalyzer. Libraries were paired-end sequenced using an Illumina HiSeq2500.

SNP calling and linkage map construction. Raw sequence files were demultiplex using scripts as described in Catchen et al. (2013). Sequences were aligned to the reference genome of Williams 82, Wm82.a2.v1 (Schmutz et al. 2010) using GSNAP pipeline (Wu et al. 2016). Binary alignment map files were sorted, ordered, and organized by Chr. as indicated by the reference genome alignment. Variants were called using GATK 3.8 and combined into master VCF file (Van der Auwera et al. 2013). Variant datum was filtered to remove indel markers, multiallelic sites, sites with $>80 \%$ missing, and sites with a depth less than 6 reads and mapping quality of 30 reads. Further filtering was performed using TASSEL 5.0 to adjust the minimum allele frequency $>0.05$, remove markers with $>65 \%$ missing data and removal of individuals with $10 \%$ or greater sites missing (Bradbury et al. 2007). Marker datum was imputed using FSFHap Imputation in TASSEL using default settings. A final marker dataset was imported into JoinMap 4.0 to generate linkage maps (Van Ooijen 2006). Nonpolymorphic markers were removed and linkage was defined using Kosambi's mapping function and independence logarithm of odds (LOD) scores of to 2.0 and greater.

Comparison of linkage map with the soybean reference genome. The SNP marker genetic position (cM) in each linkage group was aligned to the physical positions of the reference genome, Wm82.a2.v1 (Schmutz et al. 2010) using MapChart 2.3 (Voorrips 2002) as described by da Silva Linge (2018).

Identification of associated QTLs. QTL analysis was performed using MapQTL 6.0 with both normalized and $\log _{10}(x)$ transformed phenotype data (Van Ooigen 2009). Because neither format were normally distributed, both data sets were used in the analysis. Initial analysis was performed using the nonparametric Kruskal-Wallis (KW) rank sum test to identify genetic regions associated with the quantitative trait. The significance threshold for the KW test was set to $P=0.005$ for QTL detection. Significantly associated QTL regions were verified using interval mapping (IM) and multiple QTL mapping (MQM) analyses which also estimates percent phenotypic variation (Van Ooigen 2009). Genome-wide LOD thresholds were determined using permutation tests at 10,000 iterations at a $P$ value of $<0.05$. Linkage maps along with corresponding LOD-score graphs were generated using MapChart 2.3 (Voorrips 2002).

All SNP markers were run in a student's $t$ test for further verification of QTL significance. For each SNP site, the RI and genotype (A/B; William's 82/Forrest) for each individual was extracted and analyzed with a Student's $t$ test to determine if the mean phenotype for the two genotypes were statistically different $(P<0.001)$, assuming unequal variances.

Candidate genes within QTL intervals. A list of candidate genes within the three detected QTL confidence intervals was generated based on gene annotations of the reference genome, Williams 82, Wm82.a2.v1 (Schmutz et al. 2010). The list was crossvalidated by submitting and aligning the protein sequences to known sequencing in databases; KOALA, NCBI-CD, pFAM, and BLASTp (Supplementary Fig. S2). The overall effect of the SNP markers was determined using SnpEff, ver. 4.3 with the Glycine max reference genome available in the database (Cingolani et al. 2012).

\section{RESULTS}

Phenotype distribution, transformation, and clustering. The two parents of the population, which also represent the susceptible and resistant checks (Williams 82 and Forrest, respectively) in the phenotype screening had an average RI of 53.9 and 8.4, respectively. After normalization, the RI to the susceptible check and combining the data for all 250 RILs, phenotype scores ranged from 0.0335 to 7.41 with a median value of 1.64 , (Table 1 ). The distribution of the RI data were not normally distributed as indicated by the Shapiro-Wilk $(w)$ statistic normality test $(w=$ $0.930058, P<0.001$, JMP Software) (Fig. 1). The phenotype data were transformed by $\log _{10}(x)$ and both transformed and nontransformed datum formats were analyzed with an optimal univariate cluster analysis to identify a data-driven, distinct group of resistant RILs in the population (M. Klepadlo, R. T. Robbins, J. F. Wilkes, D. Crippen, V. Shankar, T. D. Vuong, P. Agudelo, and H. T. Nguyen, unpublished data). The best fit $k$-means value for the nontransformed phenotype was 4 , identifying the lowest RI cluster 
with 36 RILs (Fig. 2). In the analysis using $\log _{10}(x)$ transformation of the phenotype, the best fit $k$-means value was 2 , which divides the data into two distinct groups. The lower cluster consists of 30 lines, characterized as resistant, and the second cluster of 220 lines with higher RIs are deemed susceptible (Fig. 2). Broad-sense heritability of the RI phenotype was $H^{2}=0.81$ (Wu et al. 2009), suggesting the trait is a suitable candidate to identify genotypes associated with the phenotype.

TABLE 1. Summary of normalized reproductive index distribution of 250 recombinant inbred lines ('Forrest' $\times$ 'Williams 82 ')

\begin{tabular}{|c|c|c|c|c|c|c|c|c|}
\hline Mean & Median & Minimum & Maximum & SD & Variance & Skewness & Kurtosis & Heritability \\
\hline 1.76 & 1.64 & 0.0335 & 7.41 & 1.07 & 1.14 & 0.687 & 0.953 & 0.81 \\
\hline
\end{tabular}

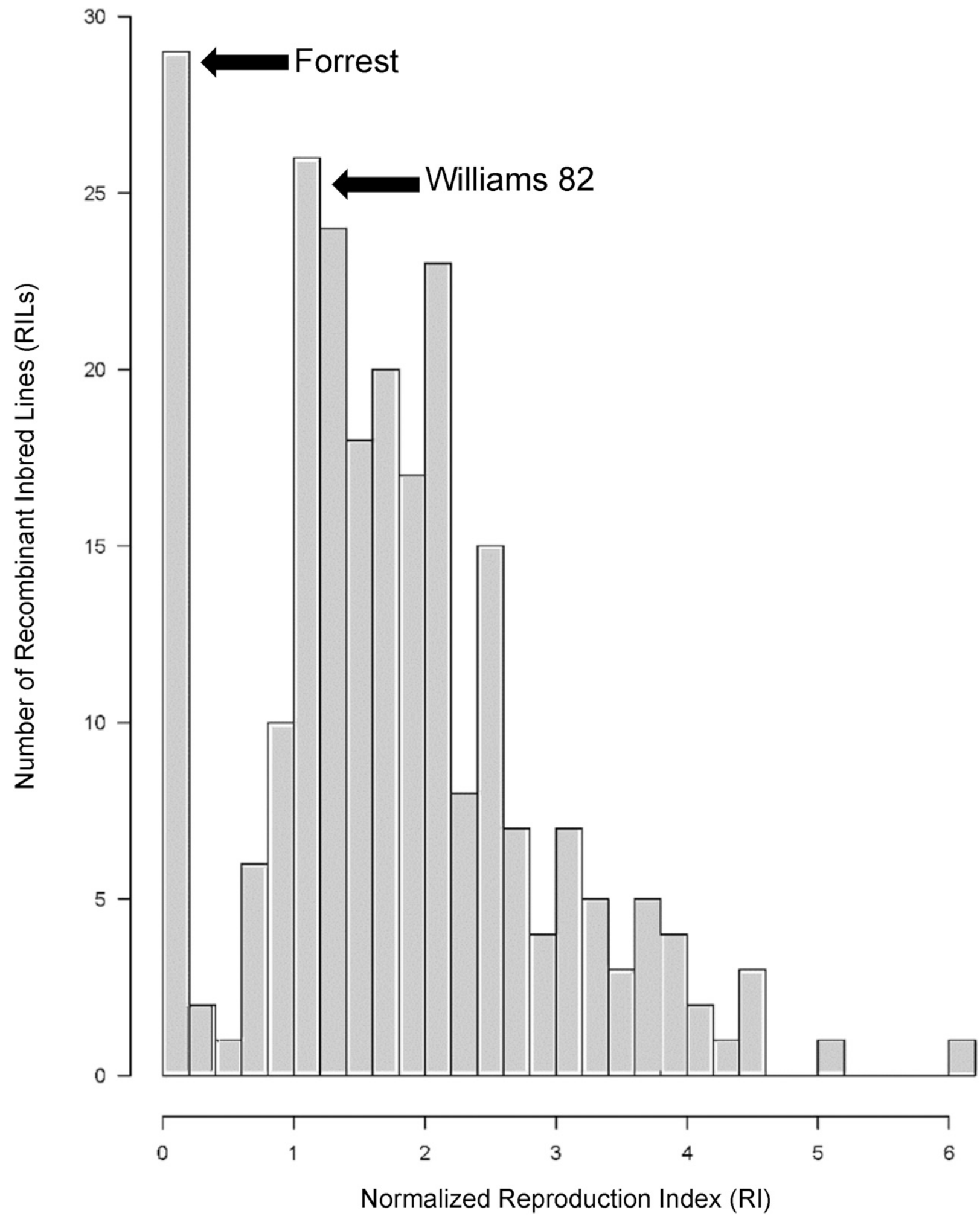

Fig. 1. Distribution of reniform nematode reproduction indices (RIs) in recombinant inbred line (RIL) population of 'Forrest' $\times$ 'Williams 82 '. 
Linkage map construction. Sequence reads totaled to $676,924,743$. After demultiplexing and filtering, an average of 4.6 million aligned reads were retained per sample with an average coverage of $0.59 \%$ of the total genome size.

SNP calling using GATK identified an initial 75,788 SNP markers in the 250 RILs, including five copies of each parent line. After filtering for quality, there were a total of 6,253 polymorphic markers and 155 individuals used in linkage map construction. Twenty-three linkage groups were constructed from 1,672 unique markers with an average of 75 markers per linkage group (Fig. 3). The total genetic distance of the linkage maps spanned 2,857.46 $\mathrm{cM}$ with an average distance of $2.19 \mathrm{cM}$ between adjacent markers. The physical distance covered by the linkage map estimated to $746 \mathrm{Mb}$ with an average genetic distance ratio of $261 \mathrm{~kb} / \mathrm{cM}$.

Alignment of linkage map to reference genome. Comparison of the genetic positions of SNP markers within the linkage groups to the physical positions on the reference genome estimated an overall alignment in $80 \%$ agreement (Supplementary Fig. S3). The Chr. with the lowest alignment score (50\%) was Chr. 13, which also had the most number of markers within a linkage group. Additionally, linkage groups corresponding to Chrs. 3, 4, 6, 8, and 9 contained at least one and as many as six markers physically mapped to a different Chr. based on the reference genome. An important note is that Chrs. 12, 14, and 15 are each represented by two linkage groups and all markers from Chr. 19 were removed during quality control.

QTL mapping. The LOD significance threshold for QTL detection was established at 3.4 based on permutation analyses using both phenotype data formats. Consensus of the KW, IM, and MQM analyses identified three QTL regions associated with host suitability to reniform nematode in the RIL population (Fig. 4). A $95 \%$ confidence interval was determined by calculating the twoLOD support interval to determine the size of each QTL region (Van Ooigen 2009). A QTL region on Chr. 18, here referred to as $r r n-1$, was significant in analyses using both normal and $\log _{10}(x)$ transformed phenotype with the highest LOD score of 3.47 and 8.28, respectively. Using nontransformed phenotype, the QTL region measured $17.677 \mathrm{cM}$ in length, covering a physical distance of $2,815,897 \mathrm{bp}(2,815 \mathrm{kbp})$. This same region from the analysis using $\log _{10}(x)$ transformed phenotype was much smaller with a

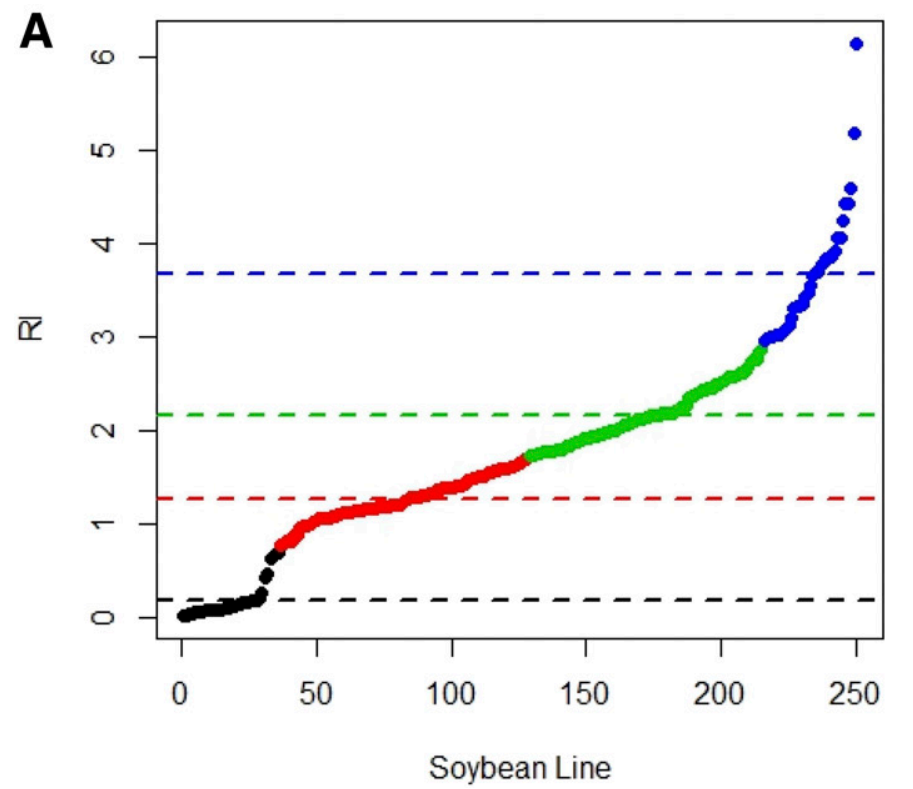

genetic length of $19.02 \mathrm{cM}$, spanning a physical distance of 3,337,828 bp (3,337 kbp). The SNP, Chr18_46 (physical position of Glyma.18g1684449), had the highest significant LOD value and a K-value of $17.513(P$ value $=0.0001)$ and was consistent in both analyses within this QTL region. The SNP marker accounted for an estimate phenotypic variance of $15.7 \%$ and additive effect of -0.383 in the nontransformed phenotype data analysis compared with a phenotypic variance of $21.9 \%$ and additive effect of -0.235 from the analysis using $\log _{10}(\mathrm{x})$ transformed data (Table 2).

A second QTL, here labeled $r r n-2$, was identified using KW and nontransformed phenotype in IM and MQM analysis. The QTL region was $12.098 \mathrm{cM}$, equal to $1,336,280 \mathrm{bp}(1,335 \mathrm{kbp})$ in length. The highest LOD score of 5.69 was at SNP marker Chr18_553 (physical position of Glyma.18g54068524) with a K-value of $30.618(P$ value $=0.0001)$. The most significant SNP in $r r n-2$ was associated with $9.9 \%$ of the phenotypic variance with an additive effect estimated to be 0.475 .

The third QTL region was identified with $\mathrm{KW}$ and $\log _{10}(x)$ transformed phenotype in IM and MQM analyses. The QTL, rrn-3, was identified on Chr. 11, covering $29.5 \mathrm{cM}$ and 593,369 bps. The SNP marker with the highest LOD value within this region was

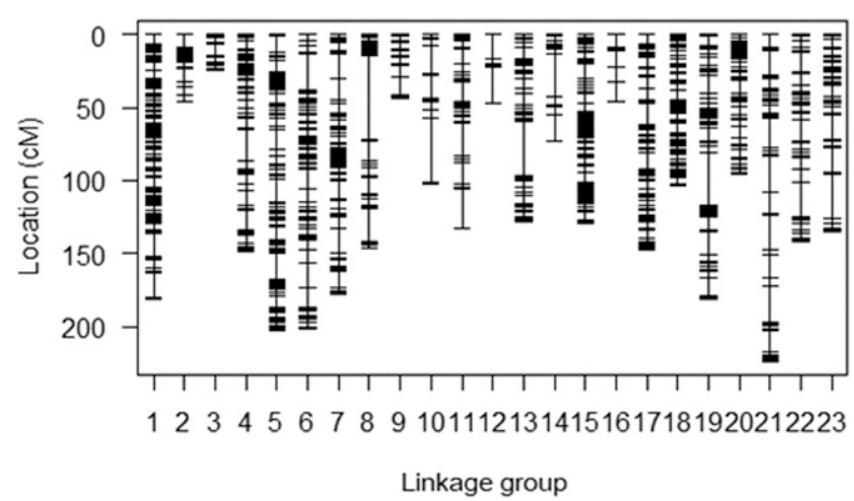

Fig. 3. Linkage map constructed with single nucleotide polymorphism markers associated with reniform nematode host suitability.

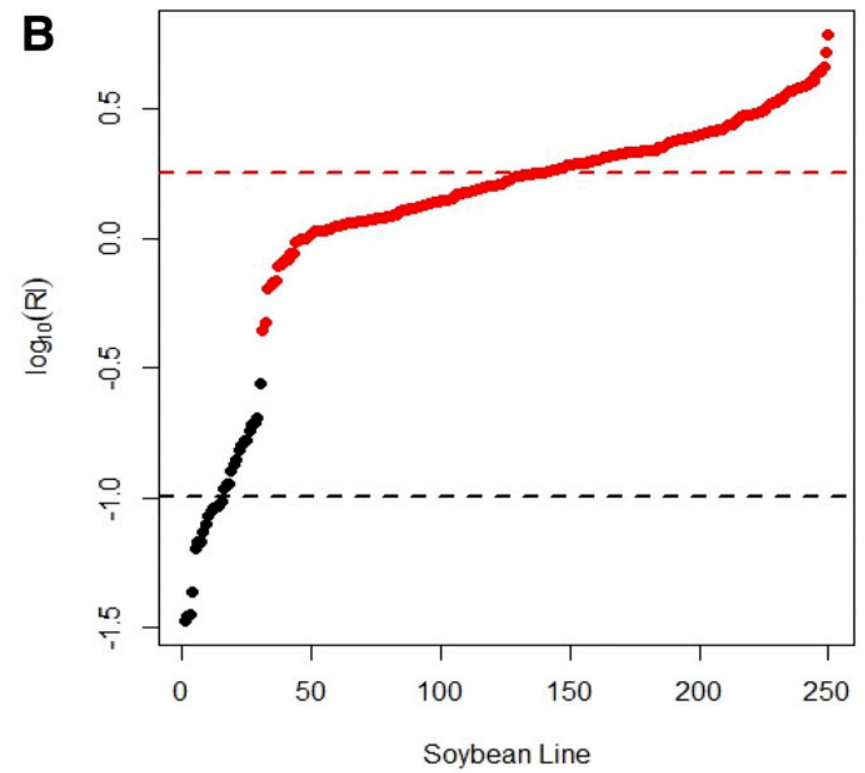

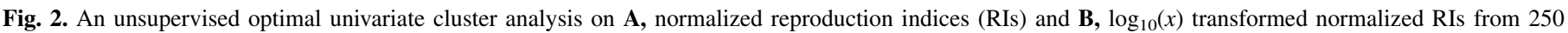
recombinant inbred lines screened with reniform nematode. 
Chr11_190 (physical position of Glyma.11g32986440) with a Kscore of 14.118 , LOD score of 8.35 , and attributed to $22.1 \%$ of the phenotypic variance (Table 2). The additive effect was estimated to be -0.235 of the normalized RI value.
Genotype association with phenotype. Of the 250 RILs, 70 carried the homozygous resistance allele for the major SNP marker in the $r r n-1$ locus and 95 individuals had the resistance allele for the major SNP marker in rrn-3, with 25 RILs with both resistant alleles.

\section{Chr 18}

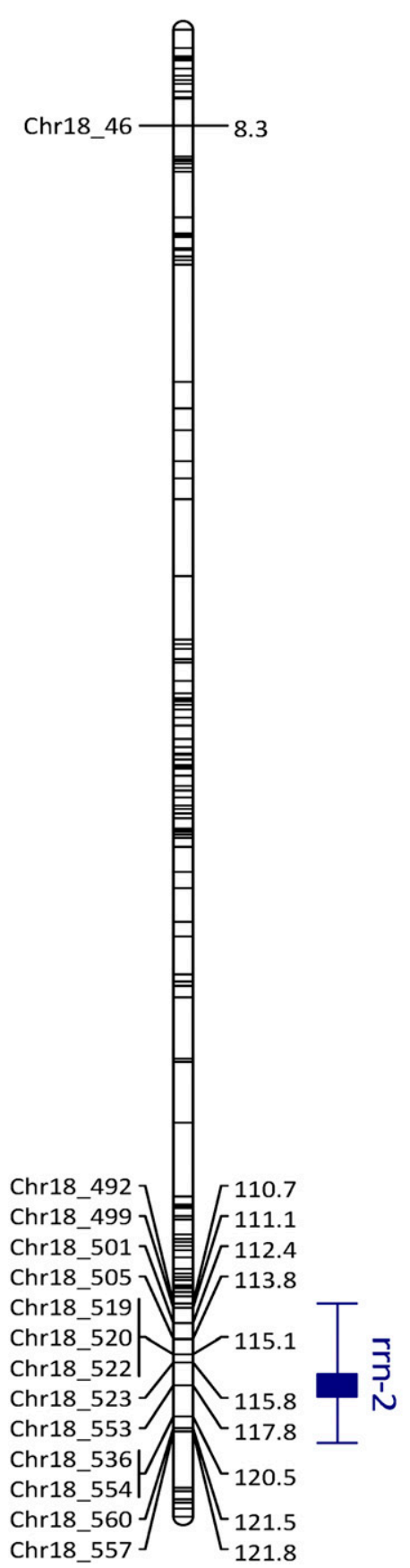

\section{Chr 11}
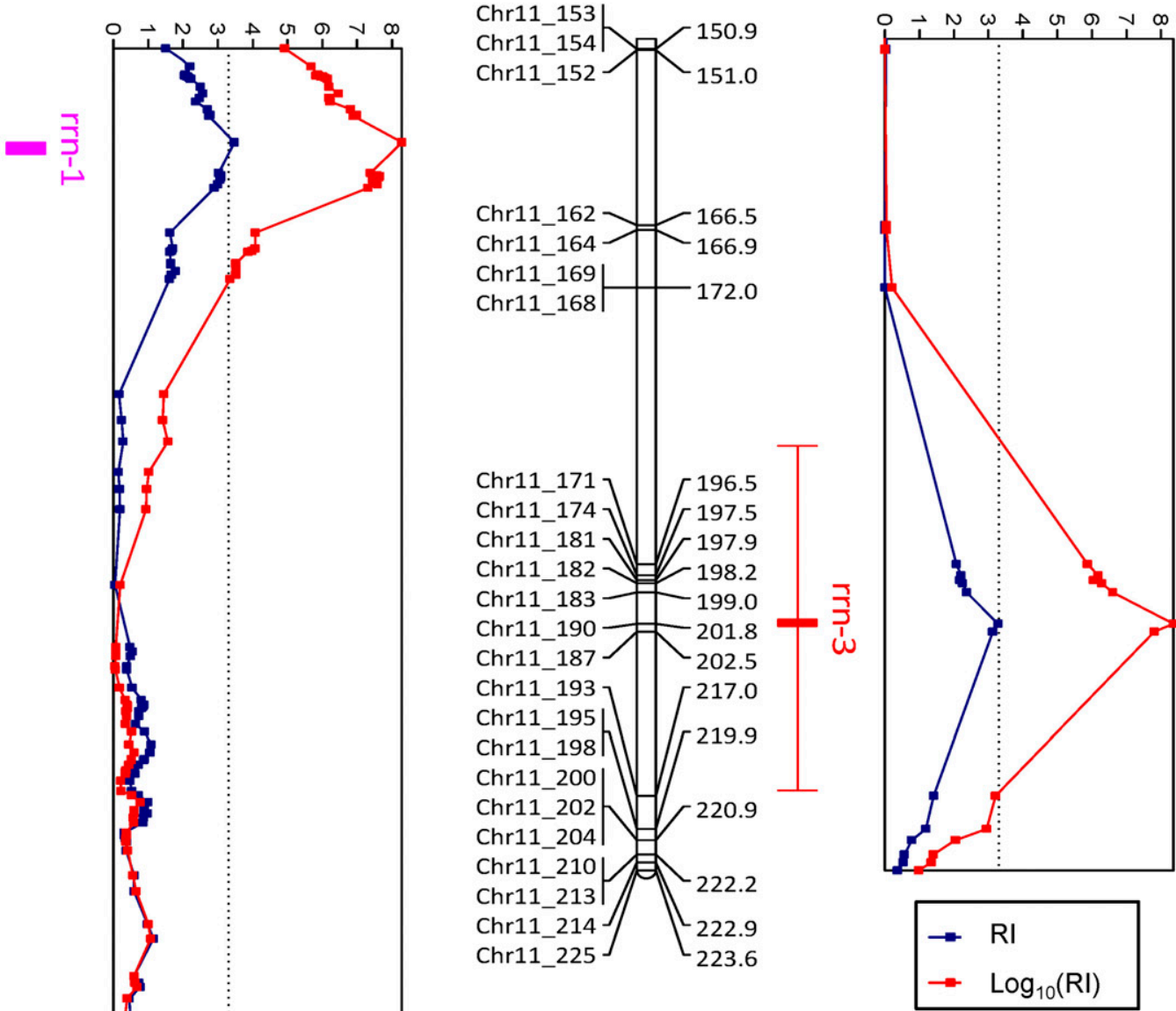

Fig. 4. Quantitative trait loci for reniform nematode resistance mapped to chromosomes 11 and 18 using normalized reproduction indices (RI, in blue) and transformed reproduction indices $\left[\log _{10}(\mathrm{RI})\right.$, in red].

TABLE 2. Summary of quantitative trait loci (QTL) associated with soybean host suitability to reniform nematode using two formats of quantitative trait data

\begin{tabular}{|c|c|c|c|c|c|c|}
\hline Phenotyping method ${ }^{a}$ & QTL & Chr. & Confidence interval & Physical position ${ }^{\mathrm{b}}$ & LOD & $R^{2}(\%)$ \\
\hline \multirow[t]{2}{*}{ RI } & $r r n-1$ & 18 & Chr18_1-Chr18_68 & $42,464-2,858,361$ & 3.47 & 15.7 \\
\hline & $r r n-2$ & 18 & Chr18_492-Chr18_557 & $52,813,203-54,091,721$ & 5.69 & 9.9 \\
\hline $\log _{10}(\mathrm{RI})$ & $r r n-1$ & 18 & Chr18_29-Chr18_68 & $1,176,342-2,858,361$ & 8.28 & 21.9 \\
\hline
\end{tabular}

${ }^{a}$ Phenotype data format in normalized reproduction indices (RI) or $\log _{10}$-transformed $\left(\log _{10}(\mathrm{RI})\right)$.

b Physical position in base pairs based on Williams 82 reference genome (Wm82.a2.v1). 
The 70 RILs with Forrest allele at the $r r n-1$ had an average RI of 1.29 (versus 2.05) and those with Forrest allele at $r r n-3$ had an average RI of 1.4 (versus 2.2). The average RI for the 25 individuals with homozygous resistant alleles at both loci was 0.33 , in contrast to an average of 2.23 for those individuals homozygous for the Williams 82 alleles at both loci. Of the 30 RILs characterized as "resistant" based on the univariate cluster analysis performed with $\log _{10}(x)$ transformed phenotype, 23 carried both resistance alleles at the two loci, three individuals had only one of the two resistance alleles, and four were not genotyped. In contrast, for $r r n-2$, the average RI values of the 71 individuals with the Forrest allele had an average RI of 2.29 compared with the reference allele average phenotype of 1.3.

The student's $t$ test showed significant differences ( $P$ value of $<0.001)$ in the mean phenotype for different parental alleles at each marker within the three QTLs. This data also illustrates the alleles contributed from Forrest in $r r n-1$ and $r r n-3$ result in a statistically significant reduction in reniform nematode reproduction (RI). Individuals with both resistant alleles at $r r n-1$ and $r r n-3$ had a lower average RI than individuals with only the allele at $r r n-1$ or $r r n-3$ (Fig. 5). However, the Forrest genotype at $r r n-2$ resulted in an increase in RI values. Only one RIL carried the alternative (Forrest) alleles at all three QTLs; therefore, the additive effect of the three resistant genotypes could not be illustrated (Fig. 5).

Candidate gene analysis. A total of 65 candidate genes were identified within the three confidence intervals. A full list of predicted gene annotations was provided in the supplemental figures (Supplemental Fig. S2). Most of the SNP markers (37 out of the 46) within the three identified QTL regions were mapped within a predicted functional gene based on their physical position within the reference genome annotation, Wm82.v1.a2. SNP markers were mapped to 23 genes in $r r n-1$, eight genes in $r r n-2$, and four genes in $r r n-3$.

It is likely that one or more of the listed annotated genes within each of the three QTL regions play a role in pathogen response or host defense. Using the SNP effect predicting algorithm, 4 of the total 36 markers within $r r n-1$ were predicted to cause a moderate impact on the gene variant. Moderate impact variants are potential changes in protein effectiveness but are still not considered highly disruptive. The majority $(57 \%)$ of the gene variants in the three QTL regions were classified as modifier, indicating gene variations in noncoding genes with an unknown level of impact (Cingolani et al. 2012). A few of the wellsupported genes within $r r n-1$ with identified SNPs include rubisco activase, nuclear pore complex protein Nup214, and a leucine-rich repeat protein domain (LRR) (Supplementary Fig. S2). Additionally, the known soybean cyst nematode resistance gene, $r h g-1$, was located $27 \mathrm{kbp}$ from the SNP marker with the highest LOD value within $r r n-1$.

In $r r n-2$, the SNP with the highest LOD score was within the soybean gene, Glyma.18g254300, a predicted leucine-rich repeat region. A second gene within this region with a detected SNP was also a predicted LRR region (Glyma.18g254600), along with a phosphopantetheine attachment site (Glyma.18g245900) and a histidine phosphatase superfamily (Glyma.18G255000). Of the 13 SNPs in $r r n-2$, six were classified as a modifier variant, creating upstream and downstream gene variants and one marker caused a synonymous variant (Table 3 ).

In $r r n-3$, the SNP with the highest LOD score was within a predicted ARM repeat superfamily protein. Two other genes were predicted in this region, one a Phosphoinositide-specific phospholipase C family protein (Glyma.11g230000), and the other a P-loop containing nucleoside triphosphate hydrolases superfamily protein (Glyma.11g232900), both confirmed in Arabidopsis orthologs (Table 3; Supplementary Fig. S2).

\section{DISCUSSION}

This is the first study to utilize a reniform nematode population collected from outside the state of Arkansas. Recent studies have shown different virulence in geographic population isolates of $R$. reniformis in the United States (Khanal et al. 2018; McGawley et al. 2011), indicating a need to test multiple population sources to

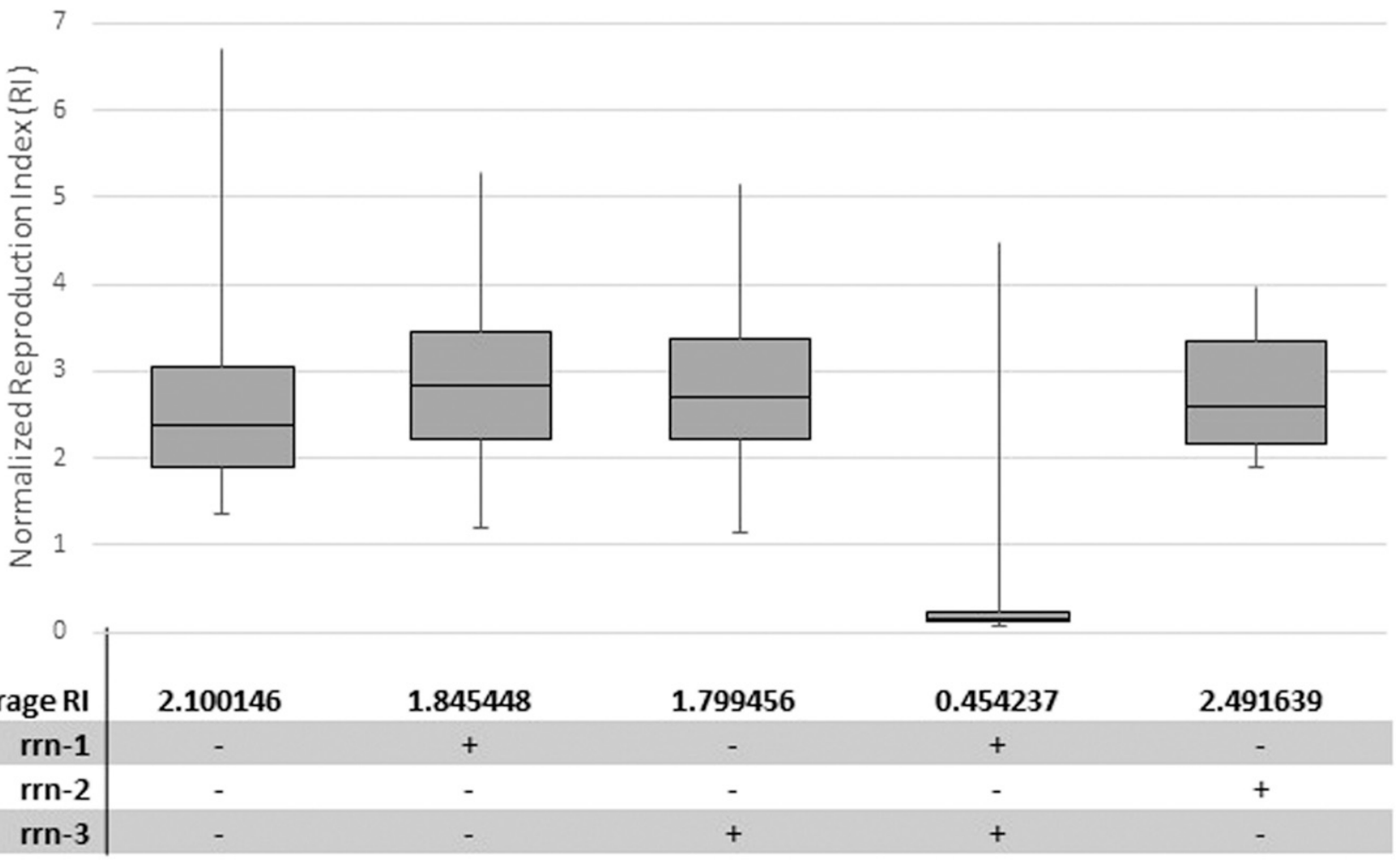

Fig. 5. Phenotypic effects of alleles in all recombinant inbred lines at each of the three identified quantitative trait loci regions. 
TABLE 3. Predicted effects of single nucleotide polymorphism alleles in soybean associated with host suitability to reniform nematode

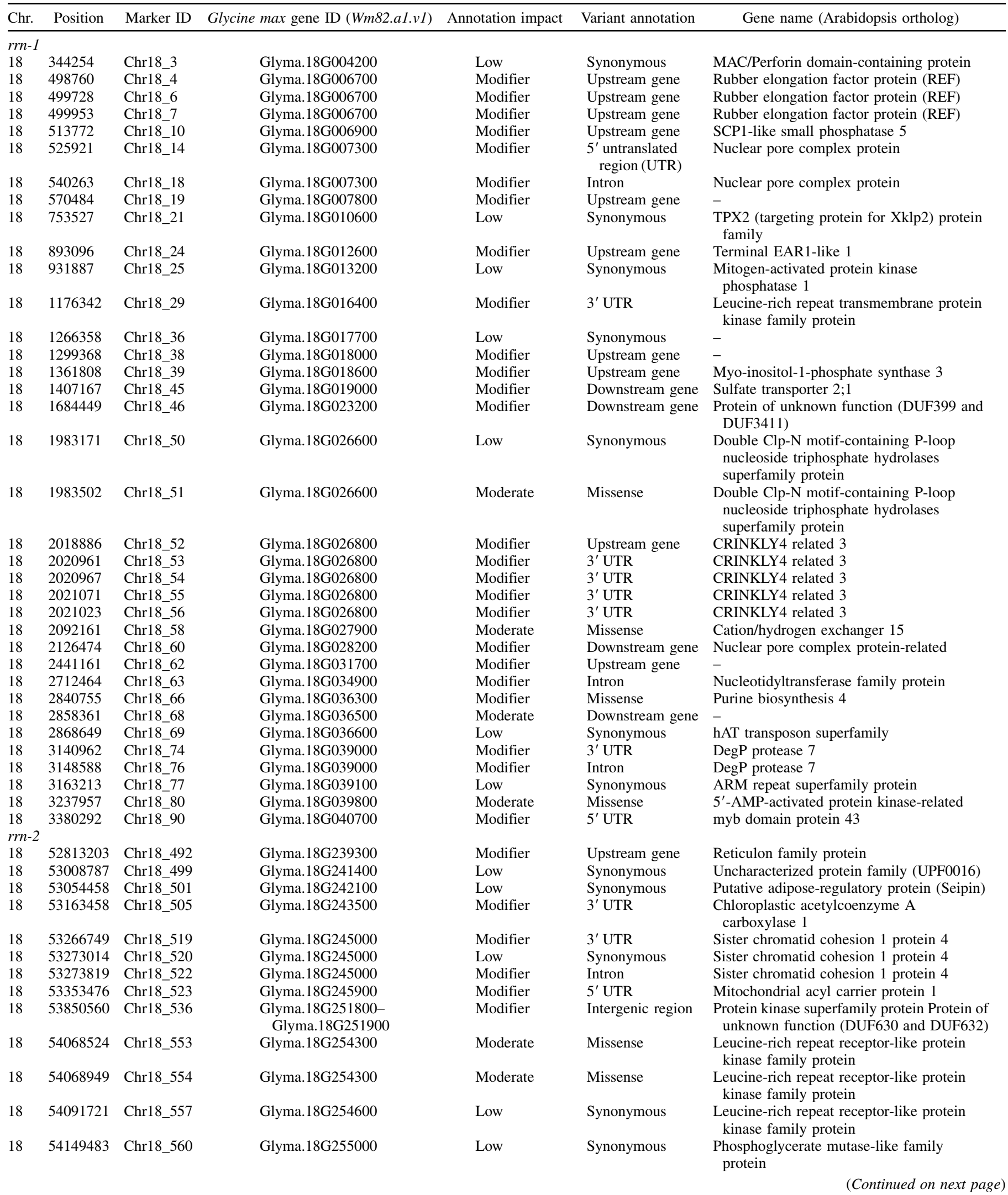


TABLE 3. (Continued from previous page)

\begin{tabular}{|c|c|c|c|c|c|c|}
\hline Chr. & Position & Marker ID & Glycine max gene ID (Wm82.a1.v1) & Annotation impact & Variant annotation & Gene name (Arabidopsis ortholog) \\
\hline \multicolumn{7}{|l|}{$r r n-3$} \\
\hline 11 & 32235891 & Chr11_171 & Glyma.11G227400 & Modifier & Upstream gene & $\begin{array}{l}\text { Mitochondrial substrate carrier family } \\
\text { protein }\end{array}$ \\
\hline 11 & 32377256 & Chr11_174 & Glyma.11G228400 & Moderate & Missense & - \\
\hline 11 & 32531257 & Chr11_181 & Glyma.11G230000 & Low & Synonymous & $\begin{array}{l}\text { Phosphoinositide-specific phospholipase C } \\
\text { family protein }\end{array}$ \\
\hline 11 & 32531669 & Chr11_182 & Glyma.11G230100 & Modifier & Upstream gene & Phospholipase C 2 \\
\hline 11 & 32696992 & Chr11_183 & Glyma.11G231300 & Modifier & Downstream gene & $\begin{array}{l}\text { Basic helix-loop-helix (bHLH) DNA- } \\
\text { binding superfamily protein }\end{array}$ \\
\hline 11 & 32829260 & Chr11_187 & Glyma.11G232900 & Moderate & Missense & $\begin{array}{l}\text { P-loop containing nucleoside triphosphate } \\
\text { hydrolases superfamily protein }\end{array}$ \\
\hline 11 & 32986440 & Chr11_190 & Glyma.11G234700 & Low & Synonymous & ARM repeat superfamily protein \\
\hline
\end{tabular}

authenticate genetic regions associated with a resistance trait for a more universal utility. Additionally, this study is the first to investigate genetic markers in the soybean cultivar Forrest that relates to reniform nematode reproduction.

Resistance and susceptibility are relative, inverse terms that are on a continuum. Performing an unsupervised univariate cluster analysis on a quantitative trait in a population of genetically related hosts captures a representative and unbiased division within the distribution.. In a biparental population, this analysis allows the distribution of the data to determine the breaking point between resistance and susceptibility, which should provide better insight on which progeny carry the resistant gene or genes. Based on our study, a cluster analysis using $\log _{10}(x)$ transformed RI provided a clearly defined separation between low and high nematode reproduction on host roots and was more conservative, identifying $30\left(\log _{10}(x)\right)$ versus 36 resistant RILs identified using nontransformed data. The 30 resistant RILs were consistent with the genotype data seen in the three detected QTL regions.

The soybean genome is a paleopolyploid, having homologous regions across the genome (Schlueter et al. 2007), which can complicate alignment of reads and map construction. This was evident during assembly of the linkage map when markers did not divide into the 20 expected linkage groups corresponding to the 20 physical Chrs. Furthermore, this might have also contributed to the several markers that mapped physically to different Chrs. than their neighboring markers in the linkage map (Supplementary Fig. S3). It is possible that some of these markers were not accurately aligned to the reference due to the vast gene duplication across the genome. Two mapped regions, $r r n-1$ and $r r n-3$, belong to a large inverted supplicated segment containing 23 conserved duplicated genes or anchors (Lakhssassi et al. 2017).

In one of the first studies to identify QTL regions related to reniform nematode in soybean, Ha et al. (2007) identified regions on Chrs. 11, 18, and 19 with the largest contributing region from Chr. 19. Raw sequence data from this study contained SNPs mapped to soybean Chr. 19 but filtration of low-quality markers and individuals removed all Chr. 19 markers from the final map used in QTL analyses. Therefore, this study does not provide enough evidence to disprove nor confirm the region on Chr.19 that was identified by Ha et al. (2007). However, exclusion of markers from Chr. 19 in the analysis may provide higher resolution of other genomic regions related to the phenotype that could have been masked otherwise.

Heritability score of 0.81 indicates the quantitative trait is highly heritable with strong genetic basis. Based on the distribution of the phenotype data, there is evidence of transgressive segregation of reniform nematode resistance trait in soybean. The transgressive index was 8.7, indicating the RIL population phenotype range exceeded that of the parental phenotype variation (Koide et al. 2019). In this case, transgressive segregation could be caused by complementary gene action (Rieseberg et al. 1999), which can be explained by epistatic interactions of different alleles at the three identified QTL regions $r r n-1, r r n-2$, and $r r n-3$.
Neither format of the phenotype data, normalized RIs and $\log _{10}(x)$ transformed, were normally distributed. Therefore, QTL regions were initially identified using the nonparametric KW analysis and the results were verified using IM, MQM analysis, and a $t$ test. All four analyses supported the three QTL regions identified to be associated with reniform nematode host suitability. Two regions, $r r n-1$ and $r r n-3$, were associated with reduced reniform nematode reproduction and one, $r r n-2$, was associated with increased reproduction on the host. An important note is that although Forrest is considered resistant to reniform nematode, it is only one source of resistance with at least 10 other lines reported statistically higher level of resistance than Forrest (Robbins and Rakes 1996). Based on this information, it is possible to suspect that genetic regions within Forrest might contribute some level of susceptibility. The use of this cultivar in a linkage analysis may have allowed for the identification of a QTL associated with reniform nematode susceptibility.

There have been previous reports of QTL regions associated with reniform nematode resistance in soybean. Four different studies which used different soybean genotypes and a reniform nematode population collected from Arkansas previously reported QTL regions that overlap rrn-1 on Chr. 18 and $r r n-3$ on Chr. 11 (Ha et al. 2007; Jiao et al. 2015; Lee et al. 2016; M. Klepadlo, unpublished data). Both these regions were identified using the $\log _{10}(x)$ transformed phenotype data and $r r n-l$ was also confirmed using normal phenotype data. This study is the first to report a region, $r r n-$ 2 on the opposite arm of Chr. 18 in association with increased susceptibility to reniform nematode. This region was identified using the normalized phenotype data, which offers a different method to analyze data to identify associated genetic regions.

Over $76 \%$ of the RILs with the two Forrest genotypes at $r r n-1$ and rrn-3 were classified to be resistant as indicated by the cluster analysis. This number may be as high as $90 \%$, since four individuals were missing genotype information. The high correlation justifies the phenotype classification methodology while confirming quality markers. The combination of both resistant genotypes at $r r n-1$ and $r r n-3$ account for a maximum of $44 \%$ of the phenotypic variance. Data indicate a greater level of resistance when individuals have resistance genotypes at both $r r n-1$ and $r r n-3$ (Fig. 5). Even after adding the nearly $10 \%$ the variance explained by $r r n-2$, there remains a significant amount of phenotypic variance that was not genetically mapped. The small percentage of full genome sequence coverage that is common of GBS techniques may contribute to the incomplete account for phenotype variation.

SNP markers pinpoint genomic neighborhoods in which certain genes might play a role on the investigated phenotype. The list of candidate genes within the mapped regions are initial steps to identify specific genes and their impact on soybean host suitability to reniform nematode development and reproduction. It is important to mention that the soybean cyst nematode resistance gene, $r h g l$, was located within the mapped $r r n-1$ interval and $R h g 4$, a paralogous gene of $r h g 1$, was located within mapped $r r n-3$ 
interval (Patil et al. 2019). Leucine-rich repeat regions were located within both $r r n-1$ and $r r n-2$ and have been reported to be linked to plant development and in some cases plant stress tolerance (Yang et al. 2014; Zhou et al. 2016) A recent study of Arabidopsis identified a highly conserved gene related to a leucine-rich repeat receptor-like kinase upregulated upon detection of parasitic nematodes (Mendy et al. 2017). It is highly possible that this gene within $r r n-2$ has some function in plant defense to reniform nematode.

In $r r n-3$, the most significant SNP was found within an ARM repeat superfamily protein, with a predicted modifier variant from the alternative allele. This protein family is known to be involved in binding ubiquitin ligase activity. Other genes of interest within the regions include the cytochrome $\mathrm{p} 450$ superfamily protein, which have many different functions, some site-specifically expressed during stress response and nodulation formation (Guttikonda et al. 2010). Also within $r r n-1$ and associated with nodulation formation was a myb-like DNA-binding domain (Du et al. 2012). A phosphoinositide-specific phospholipase $\mathrm{C}$ family protein found within $r r n-3$ has also been associated with increased expression as a response to abiotic stress (Wang et al. 2015). More investigation is required to better understand the role these SNP markers and candidate genes may play in host plant response to reniform nematode.

Conclusion. Utilization of marker-assisted selection tools are of great benefit to breeders, particularly when the markers can be easily tested and are proven to highly correlate with the phenotype of interest. This study highlights the significance of three markers from three different genomic regions associated with host suitability to reniform nematode as conveyed by the soybean cultivar Forrest. Several gene candidates within QTL boundaries were characterized for their potential role in plant host defense. However, more research is needed to narrow the region and confirm the role of specific genes in soybean response to reniform nematode infection.

\section{ACKNOWLEDGMENTS}

We thank Henry Nguyen for allowing us to utilize his soybean mapping population of RIL for resistance screening; Clemson University Genomics Institute for assisting in DNA extraction and GBS library preparation; and the lab of Ksenjia Gasic, Clemson University, for guidance in data analysis.

\section{LITERATURE CITED}

Allen, T. W., Bissonnette, K., Bradley, C. A., Damicone, J. P., Dufault, N. S., Faske, T. R., Isakeit, T., Kemerait, R. C., Koehler, A., Mehl, H. L., et al. 2018. Southern United States soybean disease loss estimates for 2018. Proc. 46th Annu. Meet. South. Soybean Dis. Work., Pensacola, FL.

Bradbury, P. J., Zhang, Z., Kroon, D. E., Casstevens, T. M., Ramdoss, Y., and Buckler, E. S. 2007. TASSEL 5.0: Software for association mapping of complex traits in diverse samples. Bioinformatics 23:2633-2635.

Catchen, J. M., Hohenlohe, P. A., Bassham, S., Amores, A., and Cresko, W. A. 2013. Stacks: An analysis tool set for population genomics. Mol. Ecol. 22: 3124-3140.

Cingolani, P., Platts, A., Wang, L. L., Coon, M., Nguyen, T., Wang, L., Land, S. J., Lu, X., and Ruden, D. M. 2012. A program for annotating and predicting the effects of single nucleotide polymorphisms, SnpEff. Fly (Austin) 6:80-92.

Concibido, V. C., Diers, B. W., and Arelli, P. R. 2004. A decade of QTL mapping for cyst nematode resistance in soybean. Crop Sci. 44:1121-1131.

Cook, D. E., Bayless, A. M., Wang, K., Guo, X., Song, Q., Jiang, J., and Bent, A. F. 2014. Distinct copy number, coding sequence, and locus methylation patterns underlie rhg1-mediated soybean resistance to soybean cyst nematode. Plant Physiol. 165:630-647.

da Silva Linge, C., Antanaviciute, L., Abdelghafar, A., Arús, P., Bassi, D., Rossini, L., Ficklin, S., and Gasic, K. 2018. High-density multi-population consensus genetic linkage map for peach. PLoS One 13:e207724.

Du, H., Yang, S.-S., Liang, Z., Feng, B.-R., Liu, L., Huang, Y.-B., and Tang, Y.-X. 2012. Genome-wide analysis of the MYB transcription factor superfamily in soybean. BMC Plant Biol. 12:106.

Edge-Garza, D. A., Rowland, T. J., Jr., Haendiges, S., and Peace, C. 2014. A high-throughput and cost-efficient DNA extraction protocol for the tree fruit crops of apple, sweet cherry, and peach relying on silica beads during tissue sampling. Mol. Breed. 34:2225-2228.
Elshire, R. J., Glaubitz, J. C., Sun, Q., Poland, J. A., Kawamoto, K., Buckler, E. S., and Mitchell, S. E. 2011. A robust, simple genotyping-by-sequencing (GBS) approach for high diversity species. PLoS One 6:e19379.

Guo, Y., Su, B., Tang, J., Zhou, F., and Qiu, L. J. 2018. Gene-based SNP identification and validation in soybean using next-generation transcriptome sequencing. Mol. Genet. Genomics 293:623-633.

Guttikonda, S. K., Trupti, J., Bisht, N. C., Chen, H., An, Y.-Q. C., Pandey, S., $\mathrm{Xu}, \mathrm{D}$., and Yu, O. 2010. Whole genome co-expression analysis of soybean cytochrome $\mathrm{P} 450$ genes identifies nodulation-specific P450 monooxygenases. BMC Plant Biol. 10:243.

Ha, B.-K., Robbins, R. T., Han, F., Hussey, R. S., Soper, J. F., and Boerma, H. R. 2007. SSR mapping and confirmation of soybean QTL from PI 437654 conditioning resistance to reniform nematode. Crop Sci. 47:1336-1343.

Hartwig, E. E., and Epps, J. M. 1973. Registration of 'Forrest' soybeans (Reg. No. 96). Crop Sci. 13:287.

Harville, B. G., Green, A., and Birchfield, W. 1985. Genetic resistance to reniform nematodes in soybeans. Plant Dis. 69:587-589.

Hussey, R. S., and Barker, K. R. 1973. Comparison of methods of collecting inocula for Meloidogyne spp., including a new technique. Plant Dis. Rep. 57:1025-1028.

Jenkins, W. R. 1964. A rapid centrifugal-flotation technique for separating nematodes from soil. Plant Dis. Rep. 48:692.

Jiao, Y., Vuong, T. D., Liu, Y., Li, Z., Noe, J., Robbins, R. T., Joshi, T., Xu, D., Shannon, J. G., and Nguyen, H. T. 2015. Identification of quantitative trait loci underlying resistance to southern root-knot and reniform nematodes in soybean accession PI 567516C. Mol. Breed. 35:131.

Khanal, C., McGawley, E. C., Overstreet, C., Stetina, S. R., Myers, G. O., Kularathna, M. T., McInnes, B., and Godoy, F. M. C. 2018. Reproduction and pathogenicity of endemic populations of Rotylenchulus reniformis on cotton. Nematropica 48:68-81.

Klepadlo, M., Meinhardt, C. G., Vuong, T. D., Patil, G., Bachleda, N., Ye, H., Robbins, R. T., Li, Z., Shannon, J. G., Chen, P., et al. 2018. Evaluation of soybean germplasm for resistance to multiple nematode species: Heterodera glycines, Meloidogyne incognita, and Rotylenchulus reniformis. Crop Sci. 58:2511-2522.

Koide, Y., Sakaguchi, S., Uchiyama, T., Ota, Y., Tezuka, A., Nagano, A.J., Ishiguro, S., Takamure, I., and Kishima, Y. 2019. Genetic properties responsible for the transgressive segregation of days to heading in rice. G3 Genes Genomes Genet. 9:1655-1662.

Lakhssassi, N., Liu, S., Bekal, S., Zhou, Z., Colantonio, V., Lambert, K., Barakat, A., and Meksem, K. 2017. Characterization of the soluble NSF attachment protein gene family identifies two members involved in additive resistance to a plant pathogen. Sci. Rep. 7:45226.

Lee, Y.-C., Lightfoot, D. A., Anderson, J., Robbins, R. T., and Kantartzi, S. K. 2016. QTL underlying reniform nematode resistance in soybean cultivar Hartwig. Atlas J. Biol. 308-312.

Lightfoot, D. A. 2008. Soybean genomics: Developments through the use of cultivar 'Forrest'. Int. J. Plant Genomics 2008:793158.

McGawley, E. C., Pontif, M. J., and Overstreet, C. 2011. Variation in reproduction and pathogenicity of geographic isolates of Rotylenchulus reniformis on soybean. Nematropica 41.

Mendy, B., Wang'ombe, M. W., Radakovic, Z. S., Holbein, J., Ilyas, M., Chopra, D., Holton, N., Zipfel, C., Grundler, F. M. W., and Siddique, S. 2017. Arabidopsis leucine-rich repeat receptor-like kinase NILR1 is required for induction of innate immunity to parasitic nematodes. PLoS Pathog 13:e1006284.

Patil, G. B., Lakhssassi, N., Wan, J., Song, L., Zhou, Z., Klepadlo, M., Vuong, T. D., Stec, A. O., Kahil, S. S., Colantonio, V., et al. 2019. Whole-genome re-sequencing reveals the impact of the interaction of copy number variants of the rhg1 and Rhg4 genes on broad-based resistance to soybean cyst nematode. Plant Biotechnol. J. 17:1595-1611.

Rebois, R. V. 1973. Effect of soil temperature on infectivity and development of Rotylenchulus reniformis on resistant and susceptible soybeans, Glycine max. J. Nematol. 5:10-13.

Rebois, R. V., Epps, J. M., and Hartwig, E. E. 1970. Correlation of resistance in soybeans to Heterodera glycines and Rotylenchulus reniformis. Phytopathology 60:695-700.

Rebois, R. V., Johnson, W. C., and Cairns, E. J. 1968. Resistance in soybeans, Glycine $\max$ L. Merr., to the reniform nematode. Crop Sci. 8:394-395.

Rieseberg, L. H., Archer, M. A., and Wayne, R. K. 1999. Transgressive segregation, adaptation and speciation. Heredity 83:363-372.

Robbins, R. T., Arelli, P., Chen, P., Shannon, G., Kantartzi, S., Fallen, B., Li, Z., Faske, T., Velie, J., Gbur, E., et al. 2017. Reniform nematode reproduction on soybean cultivars and breeding lines in 2016. Pages 184-214 in: Proc. 2016 Beltwide Cotton Conf. Dallas, TX.

Robbins, R. T., and Rakes, L. 1996. Resistance to the reniform nematode in selected soybean cultivars and germplasm lines. J. Nematol. 28:612-615.

Robbins, R. T., Rakes, L., Jackson, L. E., and Dombek, D. G. 1999. Reniform nematode resistance in selected soybean cultivars. J. Nematol. 31: 667-677. 
Robbins, R. T., Shipe, E. R., Rakes, L., Jackson, L. E., Gbur, E. E., and Dombek, D. G. 2002. Host suitability of soybean cultivars and breeding lines to reniform nematode in tests conducted in 2001. J. Nematol. 34: 378-383.

Robinson, A. F., Inserra, R. N., Caswell-Chen, E. P., Vovlas, N., and Troccoli, A. 1997. Review: Rotylenchulus species: Identification, distribution, host ranges, and crop plant resistance. Nematropica 27:127-180.

Sasser, J. N., Carter, C. C., and Hartman, K. M. 1984. Standardization of host suitability studies and reporting resistance to root-knot nematodes. Department of Plant Pathology, North Carolina State University and United States Agency for International Development, Raleigh, NC.

Schlueter, J. A., Lin, J.-Y., Schlueter, S. D., Vasylenko-Sanders, I. F., Deshpande, S., Yi, J., O'Bleness, M., Roe, B. A., Nelson, R. T., Scheffler, B. E., Jackson, S. A., and Shoemaker, R. C. 2007. Gene duplication and paleopolyploidy in soybean and the implications for whole genome sequencing. BMC Genomics 8:330.

Schmutz, J., Cannon, S. B., Schlueter, J., Ma, J., Mitros, T., Nelson, W., Hyten, D. L., Song, Q., Thelen, J. J., and Cheng, J. 2010. Genome sequence of the palaeopolyploid soybean. Nature 463:178-183.

Shi, Z., Liu, S., Noe, J., Arelli, P., Meksem, K., and Li, Z. 2015. SNP identification and marker assay development for high-throughput selection of soybean cyst nematode resistance. BMC Genomics 16:314.

Sonah, H., Bastien, M., Iquira, E., Tardivel, A., Legare, G., Boyle, B., Normandeau, E., Laroche, J., Larose, S., Jean, M., and Belzile, F. 2013. An improved genotyping by sequencing (GBS) approach offering increased versatility and efficiency of SNP discovery and genotyping. PLoS One 8: e54603.

Starr, J. L., Cook, R., and Bridge, J. 2002. Plant Resistance to Parasitic Nematodes. CABI Publishing, Wallingford, U.K.

Trudgill, D. L. 1991. Resistance to and tolerance of plant parasitic nematodes in plants. Annu. Rev. Phytopathol. 29:167-192.

Van der Auwera, G. A., Carneiro, M. O., Hartl, C., Poplin, R., Del Angel, G., Levy-Moonshine, A., Jordan, T., Shakir, K., Roazen, D., Thibault, J., et al. 2013. From fastQ data to high-confidence variant calls: The genome analysis toolkit best practices pipeline. Curr. Protoc. Bioinform. 11(1110): 11.10.1-11.10.33
Van Ooigen, J. W. 2009. MapQTL 5, Software for the mapping of quantitative trait loci in experimental populations. Kyazma B. V., Wageningen, the Netherlands.

Van Ooigen, J. W. 2006. JoinMap 4, Software for the calculation of genetic linkage maps in experimental populations. Kyazma B. V., Wageningen, the Netherlands.

Voorrips, R. E. 2002. MapChart: Software for the graphical presentation of linkage maps and QTLs. J. Hered. 93:77-78.

Wang, F., Deng, Y., Zhou, Y., Dong, J., Chen, H., Dong, Y., Wang, N., Li, X., and $\mathrm{Li}, \mathrm{H}$. 2015. Genome-wide analysis and expression profiling of the phospholipase C gene family in soybean (Glycine max). PLoS One 10: e0138467.

Wang, H., and Song, M. 2011. Ckmeans.1d.dp: Optimal k-means clustering in one dimension by dynamic programming. R J. 3:29-33.

Williams, C., Gilman, D. F., Fontenot, D. S., and Birchfield, W. 1981. Inheritance of reaction to the reniform nematode in soybean. Crop Sci. 21: 93-94

Wu, T. D., Reeder, J., Lawrence, M., Becker, G., and Brauer, M. J. 2016. GMAP and GSNAP for genomic sequence alignment: Enhancements to speed, accuracy, and functionality. Methods Mol. Biol. 1418:283-334.

Wu, X., Blake, S., Sleper, D. A., Shannon, J. G., Cregan, P., and Nguyen, H. T. 2009. QTL, additive and epistatic effects for SCN resistance in PI 437654. Theor. Appl. Genet. 118:1093-1105.

Wu, X., Vuong, T. D., Leroy, J. A., Shannon, J. G., Sleper, D. A., and Nguyen, H. T. 2011. Selection of a core set of RILs from Forrest $\times$ Williams 82 to develop a framework map in soybean. Theor. Appl. Genet. 122: 1179-1187.

Yang, L., Wu, K., Gao, P., Liu, X., Li, G., and Wu, Z. 2014. GsLRPK, a novel cold-activated leucine-rich repeat receptor-like protein kinase from Glycine soja, is a positive regulator to cold stress tolerance. Plant Sci. 215-216: 19-28.

Yu, N., and Diers, B. W. 2017. Fine mapping of the SCN resistance QTL cqSCN-006 and cqSCN-007 from Glycine soja PI 468916. Euphytica 213: 54

Zhou, F., Guo, Y., and Qiu, L. J. 2016. Genome-wide identification and evolutionary analysis of leucine-rich repeat receptor-like protein kinase genes in soybean. BMC Plant Biol. 16:58. 